\title{
Phrenic nerve stimulation in complex rehabilitation for cervical spinal cord injury using modified implantable device (case report)
}

\author{
A.N Erokhin ${ }^{1}$, A.E. Kobizev², O.M. Sergeenko ${ }^{2}$, E.F. Turovinina ${ }^{1}$
}

${ }^{1}$ Tyumen State Medical University, Tyumen, Russian Federation

${ }^{2}$ National Ilizarov Medical Research Centre for Orthopaedics and Traumatology, Kurgan, Russian Federation

\begin{abstract}
Background Cervical spinal cord injury (CSCI) can result in numerous pulmonary complications and special attention to respiratory support is vital in rehabilitation of the patients. Aim To develop regimens for an implantable generator of electrical impulses to be used in phrenic nerve stimulation to liberate or wean a patient from mechanical ventilator. Material and methods Stimulation of the phrenic nerve was performed for a 9-year-old boy with a traumatic spinal cord injury and complete anatomical disruption of the spinal cord at the C2 vertebra level. Artificial and auxiliary lung ventilation was provided for the patient with the CareFusion LTV 1200 system (USA). Nerve monitor ISIS IOM (Inomed Medizintechnik $\mathrm{GmbH}$, Germany) was used to control the phrenic nerve. Statistical analysis of baseline data was produced with two-tailed Student's t-test. Microsoft Excel and AtteStat program, version 13.1 were used to complete data analysis reports. Results A four-contact cylindrical electrode was inserted into the epidural space of the cervical vertebrae and placed at cervical levels C2-C4 with a minimally invasive procedure and a course of electrical stimulation was initiated. Possibility of weaning was considered with four step procedure to be involved. The first phase included the development and implementation of electric stimulation modes with breathing patterns at frequency of 12,15 and 20 cycles per minute with auxiliary respiration breathing. The second stage consisted of electrical stimulation with audiovisual support from animated cartoon singles. No auxiliary respiration was used with the peripheral oxygen saturation monitored in the upper limb. The third stage included phrenic nerve stimulation produced four times per day for fifteen minutes each, without assisted breathing, simultaneously with audiovisual support. The fourth stage included device implantation for chronic electrical stimulation with use of program version V18.6.2. Finally, the patient could breathe independently using simultaneous stimulation produced 3 times per day for 20 minutes and develop a greater amplitude of active head turns, improved speech clarity and increased voice volume. Conclusion Electrical phrenic nerve stimulation applied to a patient with a high level of spinal cord injury using an implantable modified device, virtual environment components and appropriate exercise therapy facilitated improved range of autonomy and level of independent breathing control.
\end{abstract}

Keywords: chronic phrenic nerve stimulation, rehabilitation

\section{INTRODUCTRION}

The optimum rehabilitation strategies based on syndromic approach [1] and respiratory support are vital for patients with severe cervical spinal cord injury. Mechanical ventilation is one of the ways to address hypoxemia but it does not compensate for decreased ventilatory lung capacity being a nonphysiological form of breathing [2]; so reduction in the duration of mechanical ventilation, weaning is critical for patients who are dependent on a ventilator [3]. The known electrical stimulation techniques include transcutaneous electrical diaphragmatic stimulation (TEDS), use of radiofrequency waves or activation of the inspiratory intercostal muscles [4], stimulation of spinal cord segments [5], direct or transcutaneous stimulation of the respiratory center [6], transvenous, radiofrequency, direct and transcutaneous stimulation of diaphragm or phrenic nerve [7]. Diaphragm pacing by phrenic nerve stimulation as an alternative to mechanical ventilation has evolved into a safe and effective modality for patients with ventilatory failure due to traumatic injury to brain stem and cervical spine, and clinical experience has been reported in three children with traumatic spinal cord injury (TSCI) at C1-C2 level [8]. The purpose of the study was to develop regimens for an implantable generator of electrical pulses to be used in phrenic nerve stimulation to liberate or wean a 9-year-old patient from mechanical ventilator. The patient was diagnosed with TSCI in the late period of the disease and complete anatomical disruption of the spinal cord at the $\mathrm{C} 2$ vertebra level. The injury occurred 15 months ago and operative stabilization performed with occipitocervical C0-C4 fusion two months ago.

\footnotetext{
Erokhin A.N, Kobizev A.E., Sergeenko O.M., Turovinina E.F. Phrenic nerve stimulation in complex rehabilitation for cervical spinal cord injury using modified implantable device (case report). Genij Ortopedii, 2020, vol. 26, no 1, pp. 89-94. DOI 10.18019/10284427-2020-26-1-89-94. (In Russian)
} 


\section{MATERIAL AND METHODS}

Phrenic nerve stimulation or diaphragm pacing was performed for the 9-year-old patient with TSCI and complete anatomical disruption of the spinal cord at the C2 vertebra level. The study was performed in accordance with ethical principles for medical research involving human subjects stated in the Declaration of Helsinki developed by the World Medical Association and recent revisions. Artificial and auxiliary lung ventilation was provided for the patient with the CareFusion LTV 1200 system (USA). Nerve monitor ISIS IOM (Inomed Medizintechnik $\mathrm{GmbH}$, Germany) was used to control the phrenic nerve. Phrenic nerve stimulation was performed with a diaphragm pacing device [9] following surgical intervention and using electrodes with four cylindrical contacts percutaneously implanted into epidural space at the C2-C4 level. The Nonin Onyx pulse oximeter (USA) was used to check oxygen saturations. Audiovisual support (virtual reality immersion) was provided with LCD television built-in DVD player and Stereo 3D Multimedia video glasses (China).
The data obtained were summarized as means (M) \pm standard deviations $(\sigma)$. The mean respiratory cycles per minute were recorded with measurements performed at one minute prior to electric stimulation, in the middle of the session and right on completion of stimulation. Number ' $n$ ' denoted the number of the above measurements produced within the first week with stimulation performed twice per day and during the second week in a similar manner. The percentage of sigma was calculated as related to the mean value of the minute, and the percentage of the mean was calculated as related to the mean measured at one minute prior to electric stimulation. The mean measured at one minute prior to electric stimulation was taken for $100 \%$. Two-tailed Student's t-test was used for primary data analysis [10]. The Shapiro-Wilk test was used to determine normality of distribution in samples. For calculations, a significance level of $p \leqslant 0.05$ was adopted. Microsoft Office Excell 2007 and AtteStat program version 13.1 were used to complete data analysis reports.

\section{RESULTS}

Neurological status measured on ASIA scale was characterized by decreased sensation at C2 level (1 $\mathrm{cm}$ lateral to the external occipital protuberance) on the right (grade 1) and on the left (grade 1); impaired sensation at C3 level (supraclavicular fossa) on the right (grade 1) and non testable on the left (grade 0). No sensory function could be testable on the right and on the left from C4 level (apex of the acromioclavicular joint) onwards. Measurements of flexor muscle strength in the forearm with the reflex center being in segment $\mathrm{C} 5$ of the spinal cord, and subsequent muscle groups graded the spinal cord injury as ASIA 0 , total paralysis, on the ASIA Impairment Scale. Complete spinal cord injury was diagnosed in the patient with absence of deep rectal sensation and anal pressure and voluntary anal sphincter contraction. Attempts were made to determine the integrity of the phrenic nerve. Minimally invasive surgical intervention was performed for the patient with electrodes with four cylindrical contacts percutaneously implanted into epidural space at the $\mathrm{C} 2-\mathrm{C} 4$ level and optimal zone of location of functional contacts identified. Motor evoked potentials were recorded intraoperatively from the diaphragm muscle and the response of 150-
$200 \mathrm{uV}$ was obtained from the right phrenic nerve. Optimal contacts for electrical stimulation were № 1 and № 2 spanning through the $\mathrm{C} 2-\mathrm{C} 3$ zone of the cervical spine. Then a 15-minute course of electrical stimulation was administered twice a day. The patient was completely subjected to assisted ventilation and could tolerate up to 2-minute spontaneous breathing. Four consecutive phases were involved in increases in off-ventilator spontaneous breathing trials. The first phase included the development and implementation of electric stimulation modes with breathing patterns at frequency of 12,15 and 20 cycles per minute. Experience with the factor used to prevent functional conditions associated with hypertraction neuropathy was practical for developing electric stimulation modes [11]. Pulse duration was $2500 \mathrm{mcs}$ with frequency fixed at $10 \mathrm{~Hz}$. Pulse train duration was $2 \mathrm{~s}$, pauses $3 \mathrm{~s}$ for the succession of respiratory movements at 12 cycles per minute; pulse train duration was $2 \mathrm{~s}$, pauses $2 \mathrm{~s}$ for 15 cycles and pulse train duration was $1 \mathrm{~s}$, pauses $1 \mathrm{~s}$ for 20 cycles. Stabilization was performed with the current generated with test device. A 15-minute course of electrical stimulation was conducted twice a day supported by auxiliary respiration breathing and 
decreased function from 11 to 7 mmAq. Breathing rate was noted to readjust to the preset mode of the phrenic nerve stimulation (Fig. 1 and 2). The readjustment phenomenon was clearly identified at the second phase with the differences in breathing rate at the 'startup-midpoint' and 'midpoint-finale' intervals being statistically significant (Table 1 ). The second stage consisted of electrical stimulation with audiovisual support from animated cartoon singles. No auxiliary respiration was used with the peripheral oxygen saturation monitored in the upper limb. The patient showed a $80 \%$ increase in off-ventilator spontaneous breathing from 9 minutes to 16 minutes 30 seconds with permanent oxygen saturation of 98-100\% within five days of the second stage (Fig. 3). The figure demonstrates dynamics in unassisted ventilation of the patient during the third week of the third stage without Pressure Support Ventilation. Observation was performed within five days with phrenic nerve stimulation produced twice a day, and nine measurements presented in the diagram. One measurement was produced on the first day. Nine minutes were taken for $100 \%$ and used for percentage increase calculations. The total length of the second stage was two weeks.

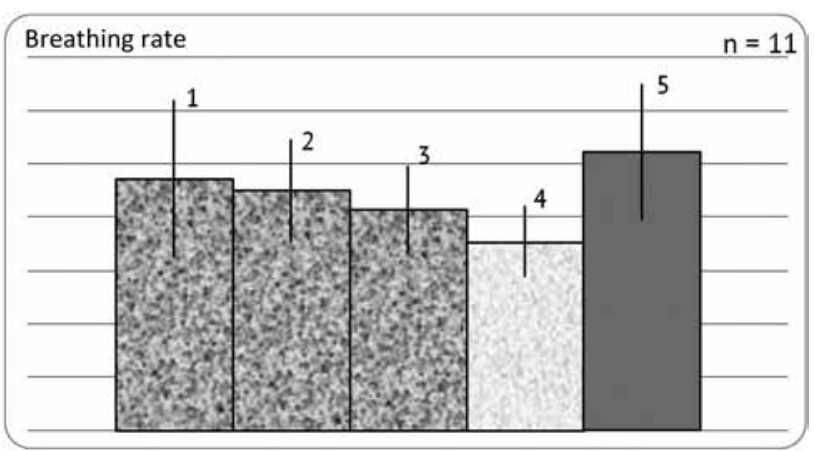

Fig. 1 Dynamics in breathing rate of the 9-yo patient $U$. who underwent phrenic nerve stimulation at the rate of 20 respiratory cycles per minute using Pressure Support Ventilation (deviation from 11 to $7 \mathrm{mmAq}$ ) during the first week of phrenic nerve stimulation: (1) prior to diaphragm pacing; (2) at midpoint of phrenic nerve stimulation; (3) finale stage; (4) minimum; (5) maximum

Unassisted breathing with phrenic nerve stimulation lasted for twenty minutes. The third four-week stage included phrenic nerve stimulation produced four times per day for fifteen minutes each, without assisted breathing, simultaneously with audiovisual support. The patient developed a greater amplitude of active head turns, improved speech clarity and increased voice volume as well as body swing while sitting.

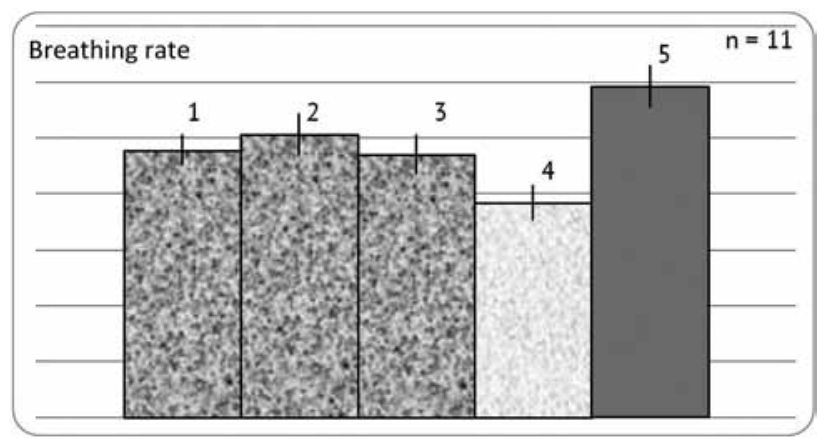

Fig. 2 Dynamics in breathing rate of the 9-yo patient U. who underwent phrenic nerve stimulation at the rate of 20 respiratory cycles per minute using Pressure Support Ventilation (permanent $7 \mathrm{mmAq}$ ) during the second week of phrenic nerve stimulation: (1) prior to diaphragm pacing; (2) at midpoint of phrenic nerve stimulation; (3) finale stage; (4) minimum; (5) maximum

Table 1

Dynamics in breathing rate (number of respiratory movements per minute) during the course of phrenic nerve stimulation (in percentages of the mean value prior to the startup, $\mathrm{M} \pm \sigma$ )

\begin{tabular}{|l|c|c|}
\hline \multicolumn{1}{|c|}{ Period } & First week & Second week \\
\hline Prior to stimulation & $100 \pm 31.1$ & $100 \pm 6.0$ \\
\hline Midpoint & $95 \pm 21.2$ & $105.7 \pm 7.5$ \\
\hline Finale & $87.7 \pm 20$ & $98.5 \pm 7.7$ \\
\hline p, startup - midpoint & 0.280219091 & 0.045566238 \\
\hline p, midpoint - finale & 0.14555315 & 0.005639159 \\
\hline
\end{tabular}

Note: two-tailed Student's t-test.

The fourth stage included device implantation for chronic electrical stimulation with use of program version V18.6.2 (Fig. 4). The patient received daily 20-minute massage and 60-minute exercise therapy throughout the four stages. At six-month follow-up, patient's mom reported her son's unassisted ventilation with simultaneous stimulation produced 3 times per day for 20 minutes maintaining functionality level achieved at the hospital.

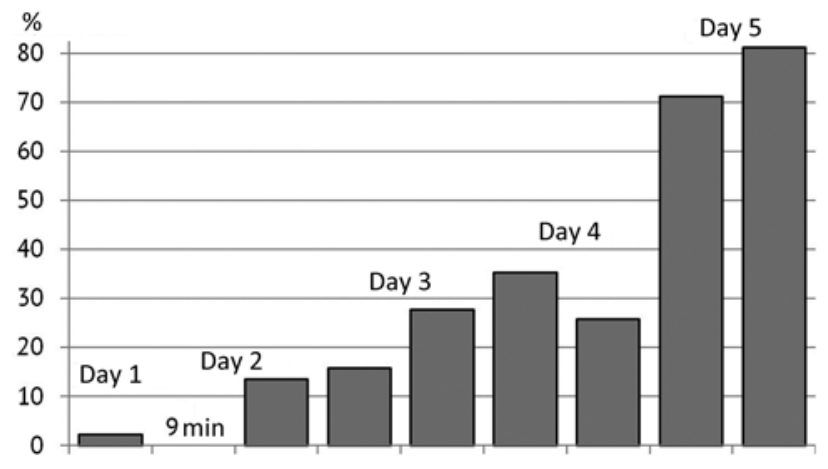

Fig. 3 Increases in off-ventilator spontaneous breathing of the 9-yo patient with diaphragm pacing + audiovisual support in percentages from 9 minutes (length of unassisted ventilation during the first session of pacing performed on the second day) within five days 


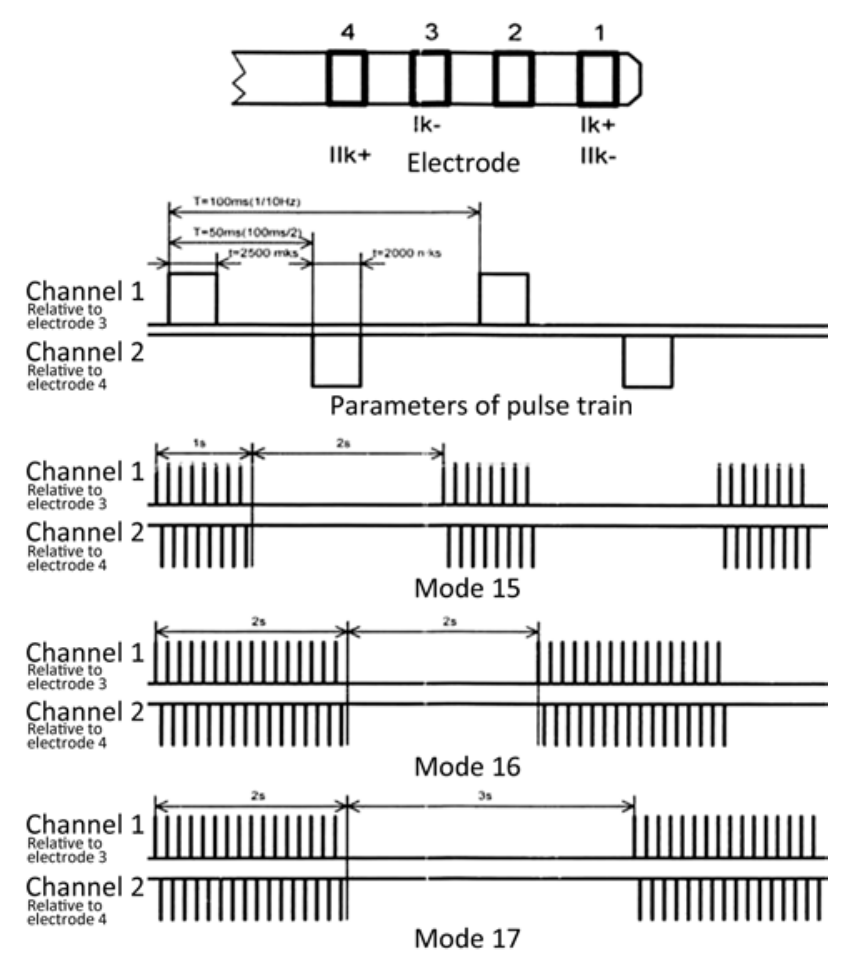

Fig. 4 Medical and technical specification of the neurostimulator

A standard four-contact cylindrical electrode was used for epidural stimulation. To incorporate a greater exposure area 1-3 contacts (electrodes) and 1-4 contacts (electrodes) were activated using two channels. The diagram shows stimulation parameters of three modes: mode № 15 referred to 20 ventilation cycles per minute ( 1 second - pulse train, 2 seconds - pause); mode № 16 referred to 15 ventilation cycles per minute (2 seconds - pulse train, 2 seconds pause); mode № 16 referred to 15 ventilation cycles per minute (2 seconds - pulse train, 2 seconds pause); mode № 17 referred to 12 ventilation cycles per minute ( 2 seconds - pulse train, 3 seconds pause).

\section{DISCUSSION}

The clinical observation presented demonstrates possibilities with phrenic nerve stimulation and audiovisual support resulting in increases in offventilator spontaneous breathing of the 9-year-old boy with a traumatic spinal cord injury and complete anatomical disruption of the spinal cord at the C2 vertebra level. Integrity of the phrenic nerves were explored following operative stabilization performed with occipitocervical $\mathrm{C} 0-\mathrm{C} 4$ fusion. Effect of pulsating direct current using current pulse generators with a four-contact cylindrical electrode inserted in the epidural space caused an evoked response from the right phrenic nerve following a course of diaphragm pacing. We could identify subtotal disruption of the spinal cord at the C2 vertebra level with partial preservation of nerve fibers forming the right phrenic nerve rather than complete anatomical disruption of the spinal cord. With optimal stimulation parameters determined, the mean respiratory cycles/minute was $23.6 \pm 7.3$ breaths $/ \mathrm{min}$. during the first week of the first stage prior to phrenic nerve stimulation, and $23.9 \pm 1.4$ breaths/min. during the second week of the first stage prior to phrenic nerve stimulation. Otherwise speaking, from the three stimulation modes developed for breathing patterns at frequency of 12 , 15 and 20 cycles per minute the latter had the innate characteristics of the patient's spontaneous breathing.

Minimum and maximum ventilation parameters were statistical characteristics indicating a variable range, and measured $17.2 \pm 32$ breaths $/$ min. and $26.0 \pm 6.3$ breaths $/ \mathrm{min}$., respectively, in the first week; and $19.2 \pm 1.6$ breaths/min. and $29.6 \pm 1.2$ breaths/ min., respectively, in the second week. If the range remained almost unchanged with slight increase of 1.5 breaths/min. in the second week, the range span moved to higher values. This could be explained by the fact that less ventilation support was provided during spontaneous breathing in the second week 
as compared to the first week (permanent $7 \mathrm{mmAq}$ versus permanent 11-7 mmAq) that required more efforts from the patient, and the range span moved to higher values indicated to greater functional potentials of the patient.

There were differences in dynamics in breathing rates throughout the course of diaphragm pacing in the first and second weeks. Stable approximation to the preset rate was observed with greater support provided in the first week and greater range shown in standard deviation. Increased ventilation rate was primarily observed in the second week followed by approximation to the preset rate with much less standard deviation than that recorded in the first week. The above dynamics in respiratory rate indicated to increased functional potentials of the patient in off-ventilator spontaneous breathing that fluctuated at midpoint and approximated to the preset rate at the finale despite less support provided in the second week. Positive dynamics in off-ventilator spontaneous breathing was observed after the course of epidural stimulation with the same ASIA score. Positive dynamics in the overall patient's functionality was seen throughout inpatient rehabilitation with improved function of the muscles innervated either above the injury level (the genioglossus muscles, the thyrohyoideus muscle, the rectus capitis anterior muscle, the rectus capitis lateralis muscle) or via cranial nerves (the platysma muscle, the digastric muscle, the mylohyoid muscle, the stylohyoid muscle). This was also confirmed by mother's subjective evaluation reporting a greater amplitude of active head turns, improved speech clarity and increased voice volume as well as body swing while her son's sitting.

\section{CONCLUSION}

An implantable modified device with three basic stimulation modes was developed for the respiratory management of a 9-year-old boy with a traumatic brain stem and cervical spine injury using the succession of pulse train with the rhythm being close to the normal respiration rate at rest. Simulation of unassisted respiration at rest and during exercise with breathing patterns at frequency of 12,15 and 20 cycles per minute allowed the patient to initiate adjustment of his respiration rate. The maximal pulse duration of 2500 mcs was employed to stimulate the maximum possible fibers of the phrenic nerve preserved. A train of pulses with the frequency of 10 $\mathrm{Hz}$ allowed for simulation of patterns of pulses being close to that in unassisted respiration. Modification of the program module in the implantable device we offered facilitated greater functionality for electric pulse generator that ultimately resulted in considerable increase in off-ventilator spontaneous breathing of the patient. The patient was able to continue phrenic nerve stimulation at home using the implantable device with automated programming of electrical stimulation featuring simple design and easy technological solution. Electrical phrenic nerve stimulation applied to a patient with a high level of spinal cord injury using an implantable modified device, virtual environment components and appropriate exercise therapy was shown to facilitate improved range of autonomy and level of independent breathing control.

No competing interests were disclosed.

\section{REFERENCES}

1. Burtsev A.V., Gubin A.V., Riabykh S.O., Kotelnikov A.O., Pavlova O.M. Sindromalnyi podkhod pri otsenke khirurgicheskoi patologii sheinogo otdela pozvonochnika [Syndromic approach in assessing the surgical pathology of the cervical spine]. Genij Ortopedii, 2018, vol. 24, no. 2, pp. 216-220. (in Russian) DOI: 10.18019/1028-4427-2018-24-2-216-220.

2. Safonov V.A., Tarasova N.N. Elektricheskaia stimuliatsiia dykhaniia [Breathing electrical stimulation]. Fiziologiia Cheloveka, 2010, vol. 36, no. 4, pp.130-142. (in Russian)

3. Davydova N.S., Boltaev P.G., Lukin S.Iu., Besedina E.A., Skorokhodova L.A., Shen N.P., Mukhacheva S.Iu. Prognosticheskaia znachimost monitoring respiratornoi biomekhaniki $\mathrm{v}$ differentsirovannoi terapii ventiliator-assotsiirovannykh legochnykh oslozhnenii $\mathrm{u}$ patsientov s tiazheloi sochetannoi travmoi s porazheniem organov grudnoi kletki [Predictive significance of respiratory biomechanics monitoring in differentiated therapy of ventilator-associated pulmonary complications in patients with severe concomitant injury and involvement of chest organs]. Meditsinskaia Nauka i Obrazovanie Urala, 2016, vol. 17, no. 2, pp.1722. (in Russian)

4. Ubaidullaeva K.M. Effektivnost metodov vosstanovleniia funktsii respiratornykh myshts u bolnykh KhOBL [Effectiveness of the methods for recovery of respiratory muscle functions in patients with chronic obstructive lung disease]. Materialy IV Nats. Kongr. po bolezniam organov dykhaniia [Materials of the IV National Congress on diseases of respiratory organs]. Klinicheskaia Meditsina Kazakhstana, 2013, no. 2 (28), pp. 98. (in Russian) 
5. DiMarco A.F., Onders R.P., Ignagni A., Kowalski K.E. Inspiratory muscle pacing in spinal cord injury: case report and clinical commentary. J. Spinal Cord Med., 2006, vol. 29, no. 2, pp. 95-108. DOI: 10.1080/10790268.2006.11753863.

6. Safonov V.A., Tarasova N.N. Vosstanovlenie dykhaniia posredstvom chrezkozhnoi elektrostimuliatsii dykhatelnogo tsentra [Breathing recovery by percutaneous electrical stimulation of the respiratory centre]. Patogenez, 2008, vol. 6, no. 1, pp. 42-45. (in Russian)

7. Shehu I., Peli E. Phrenic nerve stimulation.Eur. J.Anaesthesiol.Suppl., 2008, vol.42,pp.186-191.DOI: 10.1017/S0265021507003377.

8. Sirota S.I., Kafanova M.Iu., Polovnikov E.V. Opyt ispolzovaniia diafragmalnogo stimuliatora kak alternative traditsionnoi iskusstvennoi ventiliatsii legkickh pri ventiliatsionnoi dykhatelnoi nedostatochnosti [The experience of diaphragmal stimulator using as an alternative to traditional mechanical lung ventilation for ventilatory respiratory failure]. Trudy 6 Rossiiskogo Kongressa "Pediatricheskaia Anesteziologiia i Intensivnaia Terapiia" [Proc. $6^{\text {th }}$ Russian Congress "Pediatric Anesthesiology and Intense Therapy"]. Tver, 2011, pp. 127. (in Russian)

9. Sotnichenko V.€., Tsimbaliuk V.I., Tretiak I.B., Sapon M.A., Golovnia M.V., Slinko €.I., Shoferistov S. Sposib likuvannia khvorikh $z$ paralichem plechovogo spletennia ta pristrii dlia iogo zdiisnennia [A way of treating patients with brachial plexus paralysis and a device for its implementation]. Patent of Ukraine 59569 A61N1/18, 2002.

10.Petrie A., Sabin C. Medical Statistics at a Glance. $2^{\text {nd }}$ ed. Blackwell Publishing Ltd., 2005, 139 p. (Russ. ed.: Petri A., Sebin K. Nagliadnaia Meditsinskaia Statistika: ucheb. posobie. $3^{\text {rd }}$ ed. Moscow: GEOTAR-Media, 2015, 216 p.).

11.Erokhin A.N., Saifutdinov M.S. Profilaktika gipertraktsionnykh neiropatii u bolnykh pri chreskostnom distraktsionnom osteosinteze [Prevention of hypertraction neuropathies in the patients under transosseous distraction osteosynthesis]. Zhurnal Nevrologii $i$ Psikhiatrii im. S.S. Korsakova, 2013, vol. 113, no. 7, pp. 52-54. (in Russian)

Received: 23.09.2019

\section{Information about the authors:}

1.Aleksandr N. Erokhin, M.D., Ph.D., Tyumen State Medical University, Tyumen, Russian Federation

2. Andrei E. Kobyzev, M.D., Ph.D.,

National Ilizarov Medical Research Centre for Orthopaedics and Traumatology, Kurgan, Russian Federation

3. Olga M. Sergeenko, M.D.,

National Ilizarov Medical Research Centre for Orthopaedics and Traumatology, Kurgan, Russian Federation

4. Elena F. Turovinina, M.D., Ph.D., assistant professor,

Tyumen State Medical University, Tyumen, Russian Federation,

Email: turovinina@tyumsmu.ru 